Supplement of Hydrol. Earth Syst. Sci., 24, 2981-2997, 2020

https://doi.org/10.5194/hess-24-2981-2020-supplement

(C) Author(s) 2020. This work is distributed under

the Creative Commons Attribution 4.0 License.

(c) (1)

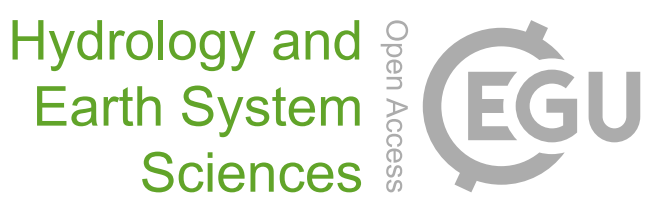

Supplement of

\title{
Impact of downscaled rainfall biases on projected runoff changes
}

Stephen P. Charles et al.

Correspondence to: Stephen P. Charles (steve.charles@csiro.au)

The copyright of individual parts of the supplement might differ from the CC BY 4.0 License. 
Figure S1 shows the empirical cumulative distribution curves for the four parameters in GR4J model, which are based on the calibration results of the 137 unregulated catchments in Victoria. The median of the four parameters are X1 $=259.3 \mathrm{~mm}, \mathrm{X} 2=-$ $0.8 \mathrm{~mm}, \mathrm{X} 3=134.3 \mathrm{~mm}$ and $\mathrm{X} 4=1.25$ days respectively. For $80 \%$ of the catchments, X1, X2, X3 and X4 are at the ranges $(1.5,1240),(-46,-0.4),(22,379)$ and $(0.5,2.1)$ respectively. It can be seen from Figure S2 that performances of GR4J at the 5137 catchments are reasonably good with NSE all above 0.5 and the median of the NSEs is around 0.69 .

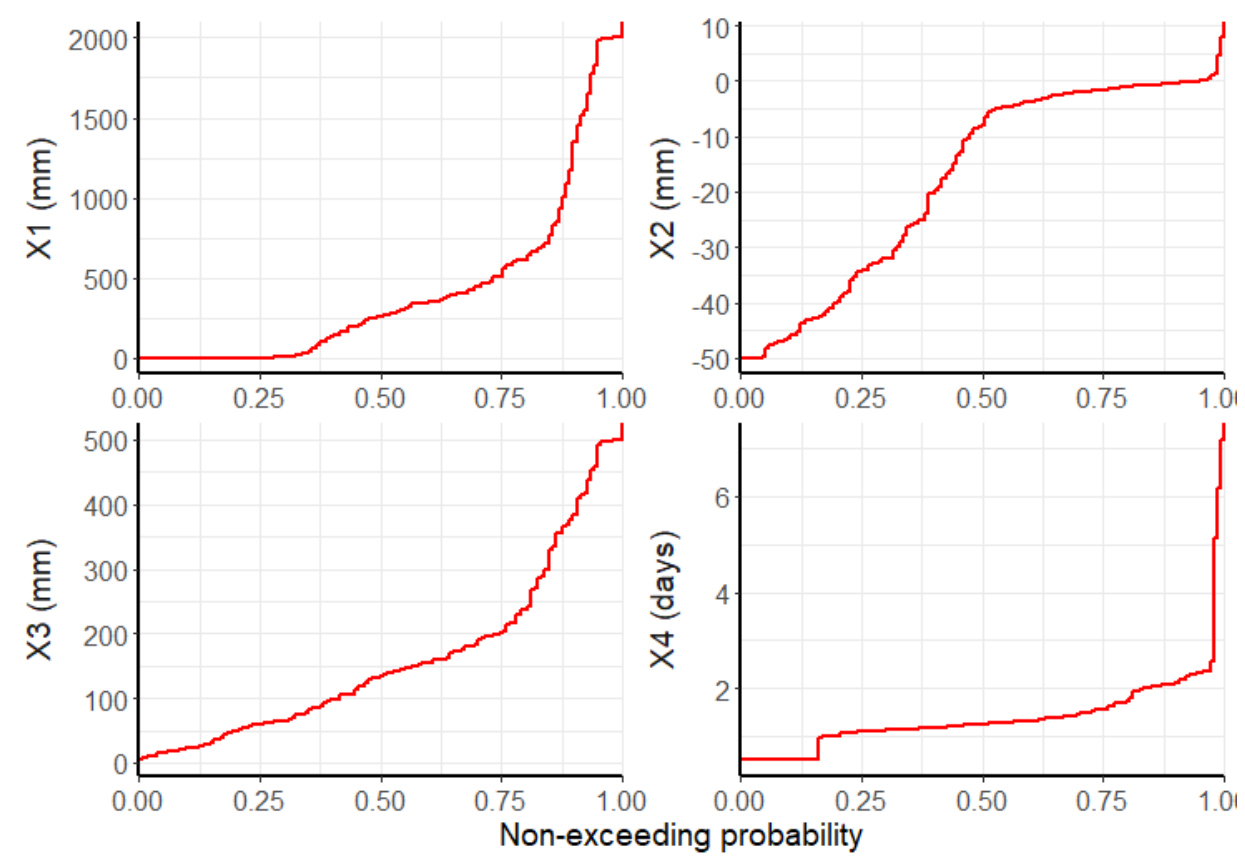

Figure S1 Empirical cumulative distribution curves of GR4J parameters based on model calibration at 137 unregulated catchments. X1 maximum capacity of the soil moisture storage $(\mathrm{mm}) ; \mathrm{X} 2$ interbasin water exchange rate $(\mathrm{mm}) ; \mathrm{X} 3$ maximum routing storage $(\mathrm{mm}) ; \mathrm{X} 4$ time base of unit hydrograph (days). 


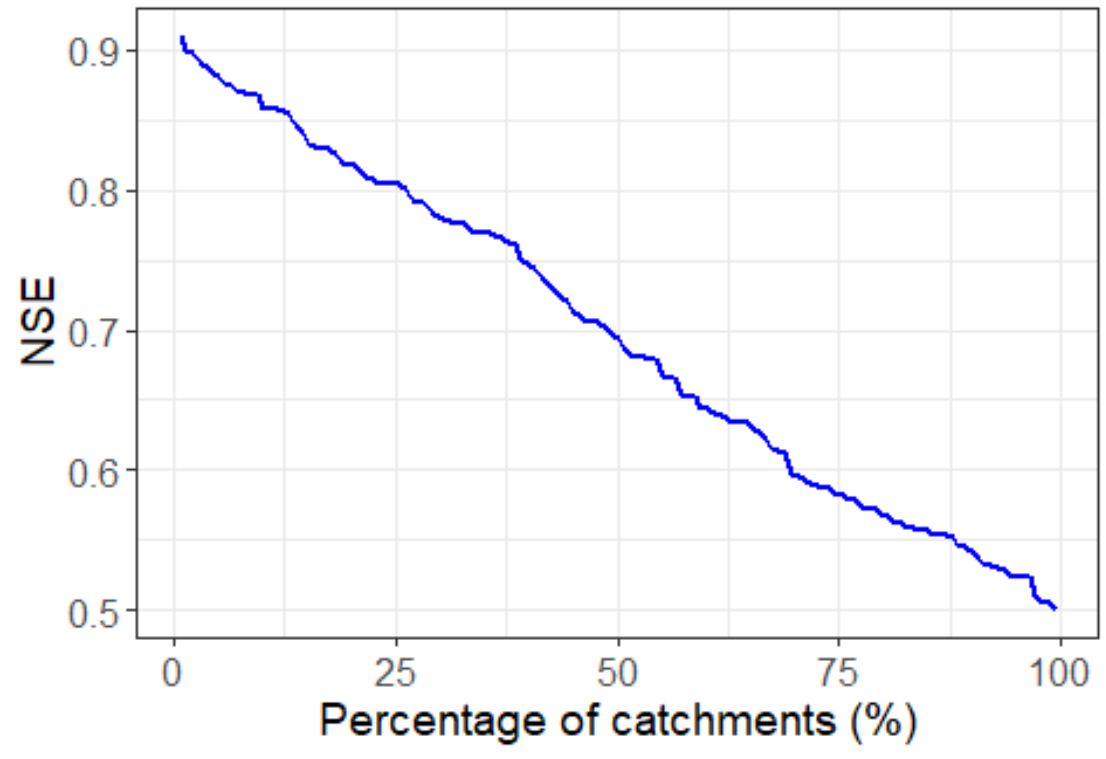

Figure S2 Performance of GR4J model calibration at 137 unregulated catchments 